\title{
Long-Term Seizures Outcome in Juvenile Myoclonic Epilepsy (JME): A Retrospective Cohort Study in an Indian Population
}

\author{
Lakshminarayanapuram Gopal Viswanathan ${ }^{1}$ Ravindranadh Chowdary Mundlamuri ${ }^{1}$ \\ Kenchaiah Raghavendra ${ }^{1}$ Ajay Asranna ${ }^{1, \odot ~ A p a r a j i t a ~ C h a t t e r j e e ~}{ }^{1} \quad$ Bhargava Gautham ${ }^{1}$ \\ Parthasarathy Satishchandra ${ }^{1}$ Sanjib Sinha ${ }^{1}$
}

${ }^{1}$ Department of Neurology, National Institute of Mental Health and Neurosciences, Bengaluru, Karnataka, India

Int J of Epilep 2021;7:15-21.
Address for correspondence Ravindranadh Chowdary Mundlamuri, DM, Department of Neurology, National Institute of Mental Health and Neurosciences, Hosur Road, Bangalore 560029, Karnataka, India (e-mail: mundlamuri.ravi@yahoo.com).

\begin{abstract}
Objectives Juvenile myoclonic epilepsy (JME) is the most prevalent form of generalized epilepsy in the community. Though the response to medication is good in most patients, long-term medication usage may lead to poor compliance, side effects, and other epilepsy-related social issues. The aim of this study was to describe the demography, clinical features, and therapeutic response in patients with JME who have had at least 10 years of duration of epilepsy.

Materials and Methods A retrospective study of 56 patients ( $M: F=26: 30$; mean age: $14.5 \pm 5.1$ years) with JME attending neurological services in a tertiary care neurological center in South India with more than 10 years disease duration was performed.

Results All patients had myoclonic jerks, $94 \%$ had generalized tonic-clonic seizure, and only $7.1 \%$ had features of absence seizures. Seizures were controlled in $60 \%$ of cases at the end of 10 years of epilepsy. Thirty-eight patients (67.8\%) were on valproate. Control of seizures at the end of the first and fifth years of epilepsy, frequent myoclonic jerks at the onset, and treatment with valproate in the first year of disease

Keywords

- juvenile myoclonic epilepsy

- prognostic factors in JME

- sodium valproate resulted in controlled seizures at the end of 10 years. No patient was off medications at the end of 10 years of epilepsy or at the last follow-up.

Conclusion About $40 \%$ of our patients continued to have seizures even 10 years after the onset of epilepsy. Regular and long-term medication may be required in JME. Early control of seizures, response to valproate, and frequent myoclonia at onset were found to confer better prognosis.
\end{abstract}

\section{Introduction}

Idiopathic generalized epilepsies (IGE) are one of the most common epilepsy syndromes encountered in clinical practice, among which juvenile myoclonic epilepsy (JME) is the most frequent subtype and accounts for nearly $10 \%$ of all epilepsies. The onset of epilepsy is usually in the peripubertal age; however, adult onset ( $>18$ years) is also well known. JME is characterized by brief myoclonic jerks published online July 30,2021
DOI https://doi.org/ 10.1055/s-0041-1729459 ISSN 2213-6320

\section{(c)2021. Indian Society of Epilepsy.}

This is an open access article published by Thieme under the terms of the Creative Commons Attribution-NonDerivative-NonCommercial-License, permitting copying and reproduction so long as the original work is given appropriate credit. Contents may not be used for commercial purposes, or adapted, remixed, transformed or built upon. (https://creativecommons.org/licenses/by-nc-nd/4.0/).

Thieme Medical and Scientific Publishers Pvt. Ltd. A-12, 2nd Floor, Sector 2, Noida-201301 UP, India 
that occur predominantly after awakening and/or after sleep deprivation associated with or without generalized seizures/ absences or both. ${ }^{1}$ In women suffering from JME, aggravation of seizure types may be observed during the perimenstrual period. The cause for this "idiopathic epilepsy" is likely to be due to genetic factors. Patients with JME usually respond exceptionally well when they are initiated on appropriate antiseizure medications (ASMs) and follow lifestyle modifications. The preferred drug is sodium valproate (SVA) but with the advent of newer drugs such as levetiracetam (LEV), SVA is no longer the drug of choice in women with epilepsy due to its side effect profile namely teratogenicity, polycystic ovarian syndrome (PCOS), and menstrual irregularity. Longterm medication usage poses a difficult challenge for both physicians and patients alike. To clarify some of these aspects and understand the natural course of the epilepsy, long-term studies are essential to advance current practice and improve overall prognosis. An attempt is being made to study the nature of this disease after a decade from disease onset.

\section{Patients and Methods}

This is a retrospective study of 56 patients who were diagnosed with JME, who had attended the neurological outpatient services in a tertiary care neurological center in South India (1983-2018). Diagnosis of JME was based on the International League Against Epilepsy (ILAE) classification criteria (1989). Study was approved by the institute ethics committee. Patients who had a duration of epilepsy of more than 10 years with at least 1 year of follow-up, who had complete information with respect to clinical details, seizure frequency, electroencephalogram (EEG) and imaging reports and treatment history were included. EEGs were done at our institute using standard protocol: 10-20 system, high filter $70 \mathrm{~Hz}$, low filter $0.1 \mathrm{~Hz}$, at least 30 minutes of recording time with hyperventilation for 3 minutes and photic stimulation at a paper speed of $10 \mathrm{~s} /$ page or $30 \mathrm{~mm} / \mathrm{second}$. EEGs done at other centers were included if they deemed to be technically sound. All EEGs were reviewed by two experienced epileptologists and were analyzed for background and interictal abnormalities, their distribution and effect of activation procedures. Demographic information, clinical features such as age at onset of epilepsy, types of seizures, frequency of seizures, therapeutic details and seizure control were documented from medical records that were maintained in the medical records department. All details pertaining to drugs and seizure control were recorded when patients visited the outpatient department (OPD) after 10 years of epilepsy onset (used for comparison among patients to maintain temporal uniformity) and also at last follow-up. Patients were considered to have controlled seizures when they had <1 generalized tonic-clonic seizure (GTCS)/year and no/very rare non-disabling myoclonia. Diagnosis of psychiatric co-morbidities, if present, were based on the opinion of a qualified psychiatrist based on Diagnostic and Statistical Manual IV/V. Statistical analysis was performed using IBM SPSS Statistics for MacOS version 24 (IBM Corp.; Armonk, New York, United States). Descriptive statistics like mean, standard deviation, and frequency were used for continuous variables. The relationship between different nominal variable was assessed using Fisher's exact test. Independent sample $t$-test was used to test the significance between nominal and continuous variables.

\section{Results}

\section{Clinical Features}

The demographic details of patients enrolled in the study same have been enlisted in - Table 1. Women constituted 53.6\% of the group. All the patients were recorded to have myoclonic jerks and 44 patients (78.5\%) had more frequent myoclonic jerks in the morning and after sleep deprivation. Four women (13.3\%) reported more myoclonia during the perimenstrual period. Eighteen patients (32.1\%) had almost daily myoclonus (daily to once every 2-3 days-frequent myoclonus) and 38 (67.9\%) had occasional myoclonus (1/week-1/month). We found that those with frequent myoclonia fared better at the end of 10 years ( $p=0.02$ ). Myoclonus in combination with GTCS was seen in up to $94 \%$ of cases. However, only 7\% ( $n=$ 4) of subjects had absence seizures. Barring one patient who had absence seizures at onset of epilepsy (which was later

Table 1 Demographics of the patients enrolled

\begin{tabular}{|c|c|c|}
\hline & Male N (\%) & Female $N(\%)$ \\
\hline Total $(n=56)$ & $26(46.4 \%)$ & $30(53.6 \%)$ \\
\hline Myoclonus $(n=56)$ & $26(100 \%)$ & $30(100 \%)$ \\
\hline GTCS $(n=53)(94.6 \%)$ & 24 & 29 \\
\hline \multirow[t]{2}{*}{ Absence $(n=4)(7.1 \%)$} & 2 & 2 \\
\hline & Mean \pm SD (y) & Range (y) \\
\hline Age at onset & $14.5 \pm 5.1$ & 6 to 26 \\
\hline Mean duration of illness & $15 \pm 5.8$ & 10 to 37 \\
\hline Duration of follow-up & $8.1 \pm 7.3$ & 1 to 33 \\
\hline Age at last follow-up & $29.7 \pm 7.2$ & $16-54$ \\
\hline First seizure type & \multicolumn{2}{|l|}{$\mathrm{N}(\%)$} \\
\hline Abnormal first EEG & \multicolumn{2}{|l|}{$34(60.7)$} \\
\hline Family history of epilepsy & \multicolumn{2}{|l|}{$9(16.0)$} \\
\hline Myoclonus & \multicolumn{2}{|l|}{$21(37.5)$} \\
\hline $\begin{array}{l}\text { GTCS with heralding } \\
\text { myoclonus }\end{array}$ & \multicolumn{2}{|l|}{$5(8.9)$} \\
\hline GTCS & \multicolumn{2}{|l|}{$29(51.8)$} \\
\hline Absence & \multicolumn{2}{|l|}{$1(1.8)$} \\
\hline \multicolumn{3}{|l|}{ Control of seizures at end of } \\
\hline 1 year & \multicolumn{2}{|l|}{$31(55.3)$} \\
\hline 5 years & \multicolumn{2}{|l|}{$38(67.8)$} \\
\hline 10 years & \multicolumn{2}{|l|}{$34(60.7)$} \\
\hline \multicolumn{3}{|c|}{ Treatment at the end of 10 years of illness } \\
\hline Monotherapy & \multicolumn{2}{|l|}{$37(66.1)$} \\
\hline Two drugs & \multicolumn{2}{|l|}{$15(26.8)$} \\
\hline Three or more drugs & \multicolumn{2}{|l|}{$4(7.1)$} \\
\hline
\end{tabular}

Abbreviations: EEG, electroencephalogram; GTCS, generalized tonicclonic seizure; SD, standard deviation. 
dominated by myoclonia), all other individuals suffered from either GTCS or myoclonus as their first seizure. Five patients had heralding myoclonus with GTCS and were included in the GTCS group. Nine individuals (16.1\%) had a positive family history of epilepsy in first-degree relatives, none of whom had history of parental consanguinity. Four patients (7.1\%) had a concomitant psychiatric co-morbidity (two suffered from depression, one from anxiety and one had adjustment disorder).

\section{Electroencephalogram}

Electroencephalography data was available for all patients. The first EEG (done at onset of epilepsy/at first visit to the OPD) was abnormal in 34 patients (60.7\%). Abnormalities were in the form in generalized frontally dominant 3 to $4 \mathrm{~Hz}$ spike/polyspike wave discharges in all patients. Four patients in addition also had focal spikes (right/left frontal). None of the patients had photosensitivity. Hyperventilation did not obviously accentuate interictal epileptiform discharge incidence in any of the EEGs. There was no difference in control of seizures between those who had first abnormal EEG compared with those who had a normal EEG ( $p=0.58)$.

\section{Imaging}

All patients had undergone either computed tomography ( $n=10)$ or magnetic resonance imaging $(n=46)$. Imaging was normal in all patients.

\section{ASMs Used and Adverse Effects in Women}

All patients were on ASMs. The first drug that was initiated in $50 \%(n=28)$ was SVA. Sodium channel blockers were the next most commonly used ASMs (carbamazepine [CBZ] and phenytoin; 7 each). None of the patients on CBZ had good seizure control. On the contrary, one patient on phenytoin did have good seizure control and continued taking the same for the next 10 years without adverse effects. At the end of 10 years of epilepsy, 38 patients (67.9\%) were on SVA, 24 of whom were on monotherapy. The next most used antiseizure medications after a decade of epilepsy were lamotrigine (LTG) and LEV. A small subset of patients was also on other ASMs (-Fig. 1).

Nineteen patients (33.9\%) required more than one drug, a decade after onset of the first seizure. Notably, four patients (7.1\%) needed three or more medications to control seizures. Three of them had occasional myoclonia and uncontrolled

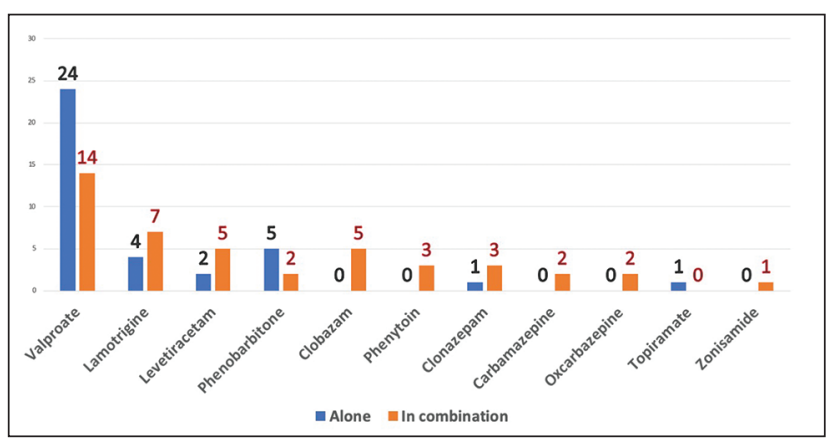

Fig. 1 Drug profile of patients with 10 years duration of illness.
GTCS. At the end of 10 years of epilepsy, 19 women had controlled seizures, of whom 12(63\%)were on SVA. Comparatively, only 4 women out of 11 (36\%) who had uncontrolled seizures were on SVA. However, this difference did not reach statistical significance $(p=0.25)$. Three of the subjects had conceived, while on SVA, two while on LEV and one woman was administered CBZ during pregnancy. All women on SVA $(n=3)$ and CBZ $(n=1)$ had an uneventful pregnancy and delivered normal children. One subject was noncompliant with SVA during pregnancy and had a generalized seizure in the eighth month of gestation. While on LEV during gestation, one woman had to undergo medical termination of pregnancy as fetal cardiac activity was absent at seventh week of gestation. Unfortunately, another young lady was on treatment with LTG (100 mg/day) had two abortions while on medication. She also had comorbid PCOS. Her epilepsy, however, remained controlled while on LTG. Two other women suffered from PCOS after being treated with SVA, one of whom underwent hysterectomy at the age of 31 due to uterine fibroids. One young lady in her twenties had recurrent seizures when SVA taper was attempted, which required her to continue with low-dose SVA+LTG. She had deferred conception as she was on two antiseizure medications. Another patient was switched over to oxcarbazepine with zonisamide but continued to have uncontrolled seizures. Alternative medications such as LEV and LTG could not be reinstated due to intolerable adverse effects (suicidal ideations and skin rash respectively). She is yet to start a family as she still requires multiple medications. Two married women who were on SVA have separated from their spouses and are yet to conceive. None of the patients were off medications, neither at the end of 10 years nor at the last follow-up.

\section{Control of Seizures at the End of 10 Years Duration of Epilepsy}

Ten years into epilepsy $60.7 \%(n=34)$ of the individuals had well controlled seizures. Among the 22 who had uncontrolled seizures (39.3\%), 12 were on SVA or a combination with SVA. Control of seizures in the first year and after 5 years of epilepsy onset was associated with better control at the end of 10 years ( $p=0.03$ and 0.007 , respectively). It was also noted that treatment with valproate in the first year of disease was associated with better control seizures at the end of 10 years of epilepsy ( $p=0.005)$. Age at onset, gender, type of first seizure (GTCS/myoclonus), treatment with SVA between 5 and 10 years were not associated with any significant difference with respect to seizure control (-Table 2 ).

Forty-seven patients (83.9\%) had followed up beyond 10 years of disease duration (range: 11-37 years). Seventy-two percent of patients $(n=34)$ were seizure free at their last follow-up (range: 12-37 years of disease duration). There was no significant difference in seizure control outcomes with respect to baseline seizure frequency, gender, age at onset, coexisting psychiatric disturbances, EEG findings, and seizure control at 1 year/ 1 to 5 years of epilepsy. None of the patients were off medications and attempts to taper resulted in seizure recurrence (GTCS) in eight out of eight patients. 
Table 2 Control of seizures after 10 years of illness

\begin{tabular}{|c|c|c|c|}
\hline & $\begin{array}{l}\text { Controlled seizures after } 10 \\
\text { years of illness }(n=34) \\
N(\%)\end{array}$ & $\begin{array}{l}\text { Uncontrolled seizures after } \\
10 \text { years of illness }(n=22) \\
N(\%)\end{array}$ & $p$-Value (2-sided) \\
\hline \multicolumn{4}{|l|}{ Age at onset } \\
\hline$<18 y$ & $23(41.1)$ & $17(30.4)$ & \multirow[t]{2}{*}{$0.55^{\mathrm{a}}$} \\
\hline$>18$ years & $11(19.6)$ & $5(8.9)$ & \\
\hline Mean age at onset $(n)$ & $15.3+4.4 y(34)$ & $13.4+6.0 y(22)$ & $0.19^{b}$ \\
\hline \multicolumn{4}{|l|}{ First seizure type } \\
\hline GTCS & $22(39.3)$ & $12(21.4)$ & \multirow[t]{2}{*}{$0.58^{a}$} \\
\hline Myoclonus & $12(21.4)$ & $9(16.1)$ & \\
\hline \multicolumn{4}{|l|}{ Frequency of myoclonus } \\
\hline Almost daily & $15(26.8)$ & $3(5.4)$ & \multirow[t]{2}{*}{$0.02^{\mathrm{a}}$} \\
\hline Occasional/infrequent & $19(33.9)$ & $19(33.9)$ & \\
\hline \multicolumn{4}{|l|}{ Gender } \\
\hline Male & $15(26.8)$ & $11(19.6)$ & \multirow[t]{2}{*}{$0.79^{\mathrm{a}}$} \\
\hline Female & $19(33.9)$ & $11(19.6)$ & \\
\hline \multicolumn{4}{|l|}{ Family history of epilepsy } \\
\hline Absent & $28(50.0)$ & $19(33.9)$ & \multirow[t]{2}{*}{$>0.99^{\mathrm{a}}$} \\
\hline Present & $6(10.7)$ & $3(5.4)$ & \\
\hline \multicolumn{4}{|l|}{ Controlled at 1 year } \\
\hline Yes & $23(41.1)$ & $8(14.3)$ & \multirow[t]{2}{*}{$0.03^{\mathrm{a}}$} \\
\hline No & $11(19.6)$ & $14(25.0)$ & \\
\hline \multicolumn{4}{|l|}{ Controlled at 5 years } \\
\hline Yes & $28(50.0)$ & $10(17.9)$ & \multirow[t]{2}{*}{$0.007^{a}$} \\
\hline No & $6(10.7)$ & $12(21.4)$ & \\
\hline \multicolumn{4}{|l|}{ First EEG findings } \\
\hline Normal & $12(21.4)$ & $10(17.9)$ & \multirow[t]{2}{*}{$0.58^{\mathrm{a}}$} \\
\hline Abnormal & $22(39.3)$ & $12(21.4)$ & \\
\hline \multicolumn{4}{|c|}{ SVA started in first year of illness } \\
\hline Yes & $23(41.1)$ & $5(8.9)$ & \multirow[t]{2}{*}{$0.02^{\mathrm{a}}$} \\
\hline No & $11(19.6)$ & $17(30.4)$ & \\
\hline \multicolumn{4}{|c|}{ SVA at the end of 10 years of illness } \\
\hline Yes & $26(46.4)$ & $12(21.4)$ & \multirow[t]{2}{*}{$0.14^{\mathrm{a}}$} \\
\hline No & $8(14.3)$ & $10(17.9)$ & \\
\hline \multicolumn{4}{|c|}{ Monotherapy at the end of 10 years of illness } \\
\hline Yes & $25(44.6)$ & $12(21.4)$ & \multirow[t]{2}{*}{$0.16^{\mathrm{a}}$} \\
\hline No & $9(16.1)$ & $10(17.9)$ & \\
\hline
\end{tabular}

Abbreviations: EEG, electroencephalogram; GTCS, generalized tonic-clonic seizure; SD, standard deviation; SVA, sodium valproate.

aFisher's exact test.

bIndependent $t$-test.

\section{Discussion}

\section{Clinical Profile and Medication Profile}

JME requires long-term treatment, possibly even lifelong due to a persistent risk of recurrence of seizure on stopping medication. We attempted to study the profile of such patients after 10 years of onset of epilepsy. The age at onset in our group of patients is comparable to other Indian studies in published literature. ${ }^{2,3}$ Men and women were nearly equally affected. Notably, the number of patients who had absences constituted only $7 \%$ of the cases. This is surprisingly lower than other large studies that have reported up to a third of patients with JME having absences. ${ }^{4-6}$ This is possibly due to a smaller sample size and due to the inherent heterogeneity of seizure types in JME. Traditionally, patients with JME are assumed to have a higher risk of developing personality disorders and psychiatric disturbances. Our cohort had four individuals with known psychiatric disorders. A study 
comprising of 41 cases of JME followed up over 20 years surprisingly found good psychosocial outcomes in the long term but it was found that the presence of psychiatric comorbidities did affect the quality of life. ${ }^{7}$ For many decades, SVA has been the go-to drug for neurologists when dealing with JME. A considerable number of patients maintain good seizure control even with low dosages of SVA. ${ }^{8}$ In our study, we found that treatment with SVA in the first year of epilepsy predicted good seizure control up to 10 years into epilepsy. Up to $82 \%$ of patients who were given SVA initially did well throughout the course of their epilepsy, which is comparable to another study wherein seizure control after administration of SVA as the initial drug was reviewed. ${ }^{9}$ Whether SVA in some way has a disease modifying effect on the course of JME is unknown and will require larger prospective studies. Due to mounting evidence that implicates SVA as a teratogen and due to its ill-effects on the menstrual cycle, it has slowly lost favor with many worldwide..$^{10-12}$ In this study, we found infrequent occurrence of SVA-induced PCOS. This could be due to nonconsecutive sampling and the retrospective nature of the study. It is to be noted that $63 \%$ $(n=12)$ of women who had excellent seizure control were using SVA without side effects in all but one woman. The use of SVA in women of childbearing age group thus must be individualized. ${ }^{13}$ Alternatively, LEV and LTG may be used but their efficacy is inferior to that of SVA in JME. In this study, we found that LEV seldom offers complete seizure control as monotherapy and over the course of the disease; and in most cases, another ASM may be required to control the seizures.

\section{Prognostic Indicators for Seizure Control in JME}

Certain forms of IGE such as epilepsy with grand-mal on awakening have good long-term outcomes. ${ }^{14}$ JME is considered by many as a genetically mediated epilepsy requiring long term, if not lifelong treatment. Nevertheless, this notion has been challenged by a few studies. ${ }^{15,16}$ There are observations alluding to the idea that all JMEs are not the same and there are some subgroups/endophenotypes that are likely to do better than others. It has been hypothesized that the presence of all seizure types (absence, myoclonus and GTCS) predicts a poorer prognosis in JME and those with only myoclonia do better. ${ }^{6,17-19}$ We found that frequent myoclonus (almost daily) was a good predictor of seizure outcomes. This group of patients probably belongs to a subsyndrome of JME who have good response to medication. The number of patients affected with absences was few; we could not definitively comment regarding its prognostic significance. We also did not find any association between age/gender/type of seizure at onset and seizure control at the end of a decade or last follow-up.

One of the findings we wish to highlight is that early control of seizures (within the first 5 years of epilepsy) did result in better outcomes at the end of 10 years of epilepsy. This has also been reported previously. ${ }^{20}$ Intuitively, response to medications early in the course of epilepsy is a plausible predictor of better long-term outcomes. There was no difference in long-term seizure control between groups that were on monotherapy versus those who were on more than one drug. Addressing factors such as poor compliance and adherence to treatment and prospectively studying if there will be a difference between these two groups would be necessary before drawing any further conclusions. Only $60 \%$ of our patients had good seizure control after 10 years that is lesser than previously reported. ${ }^{21}$ This is likely due to a selection bias, as the individuals who had good seizure control likely did not follow-up for longer periods and probably took

Table 3 Prognostic factors in long-term follow-up studies in JME

\begin{tabular}{|c|c|c|c|c|}
\hline Author (y) & No. of subjects & $\begin{array}{l}\text { Duration of } \\
\text { epilepsy in } \\
\text { years }\end{array}$ & $\begin{array}{l}\text { Follow-up in } \\
\text { years }\end{array}$ & Observations \\
\hline Holtkamp et al ${ }^{7}$ (2014) & 41 & $46.3^{\mathrm{a}}(20-69)^{\mathrm{b}}$ & $46.3^{\mathrm{a}}(20-69)^{\mathrm{b}}$ & $\begin{array}{l}\text { Psychiatric comorbidities associated with poor } \\
\text { quality of life }\end{array}$ \\
\hline Calleja et al $(2001)^{9}$ & 22 & - & $7.7^{\mathrm{a}}(5-17)^{\mathrm{b}}$ & $\begin{array}{l}\text { Valproate treatment early in the course of epi- } \\
\text { lepsy portends to better prognosis }\end{array}$ \\
\hline Senf et al $(2013)^{6}$ & 66 & $44.6^{a}(20-69)^{b}$ & $44.6^{\mathrm{a}}(20-69)^{\mathrm{b}}$ & $\begin{array}{l}\text { Presence of absence seizures at onset associated } \\
\text { with poorer seizure control }\end{array}$ \\
\hline Stevelink et al (2019) & 3311 (meta-analysis) & - & - & $\begin{array}{l}\text { One-third of JME patients have refractory } \\
\text { seizures. Presence of all three seizure types, pre- } \\
\text { existing childhood absence, and praxis induced } \\
\text { seizures are predictive of poorer outcome }\end{array}$ \\
\hline Jain et al $(1997)^{18}$ & 15 & NA & NA & $\begin{array}{l}\text { Patients who have myoclonia alone have good } \\
\text { seizure control and could represent a separate } \\
\text { endophenotype of JME }\end{array}$ \\
\hline Guaranha et al $(2011)^{20}$ & 65 & $10.73^{\mathrm{a}}$ & At least 3 years & $\begin{array}{l}\text { Presence of all three types of seizures, younger } \\
\text { age at onset, more frequent seizures at onset, } \\
\text { and praxis/language induced myoclonus have } \\
\text { prognostic implications }\end{array}$ \\
\hline
\end{tabular}

Abbreviation: JME, juvenile myoclonic epilepsy.

aMean.

bRange. 
further care from local neurologists. A summary of follow-up studies that have looked into various prognostic factors in JME has been tabulated in - Table 3.

EEG signatures have not been found to have any predictive value in JME and we also found no differences between EEG abnormalities and seizure control. ${ }^{22}$ We also did not find spike wave discharges at frequencies above 5 to $6 \mathrm{~Hz}$ that is relatively common in JME. This is probably due to the retrospective nature of the study and nonconsecutive sampling. Certain findings such as photosensitivity may have a prognostic value but strong evidence of the same is lacking. Reflexive components in JME such as photosensitivity could indicate the presence of underlying monogenic abnormalities. Genetics in JME is sure to play a role in prognostication in the future. Numerous genetic studies have been conducted in the south Indian population that have looked into the role of various genes(e.g., EFHC1, BRD2, KCNQ3, and GABRA1).23-26 A clear genotype-phenotype correlation has still not been conclusively proven as this is probably determined by a complex interaction between genetic and environmental factors. In a study that looked into the effects of EFHC1 in long-term seizure outcomes in JME, the authors found that certain single nucleotide polymorphisms were associated with poorer prognosis, lesser chances of seizure freedom in the long term, and higher risk of status epilepticus. ${ }^{27}$ More studies will be needed to ascertain genetic prognostic factors in JME.

\section{Conclusions and Limitations}

Our study has many limitations as it's a retrospective study. Follow-up was not uniform in patients and hence we had taken wide intervals ( 1 year, 5 years, and 10 years of disease duration) for assessing seizure control and a larger study group may have yielded more information. In addition, follow-up of longer periods is ideal to know more about seizure control after the fourth decade. Also, seizure occurrence, especially myoclonia, was recorded by patient's recall at hospital visit. This may be subject to an element of recall bias. The strength of this study is that we could obtain information regarding the course of JME for up to 10 years for 56 patients. Long-term outcome studies in JME in the setting of an Indian population are lacking. Prospective and well-structured follow-up studies with more numbers are needed to throw more light on prognosticating patients with JME and identify those who can be, if at all, withdrawn from ASMs in the long term.

\section{Funding}

None.

\section{Conflict of Interest}

None declared.

\section{References}

1 Kasteleijn-Nolst Trenité DGA, de Weerd A, Beniczky S. Chronodependency and provocative factors in juvenile myoclonic epilepsy. Epilepsy Behav 2013;28(Suppl 1):S25-S29
2 Chakravarty A, Mukherjee A, Roy D. Observations on juvenile myoclonic epilepsy amongst ethnic Bengalees in West Bengalan Eastern Indian State. Seizure 2007;16(2):134-141

3 Murthy JMK, Rao CM, Meena AK. Clinical observations of juvenile myoclonic epilepsy in 131 patients: a study in South India. Seizure 1998;7(1):43-47

4 Vijai J, Cherian PJ, Stlaja PN, Anand A, Radhakrishnan K. Clinical characteristics of a South Indian cohort of juvenile myoclonic epilepsy probands. Seizure 2003;12(7):490-496

5 Panayiotopoulos CP, Obeid T, Tahan AR. Juvenile myoclonic epilepsy: a 5-year prospective study. Epilepsia 1994;35(2):285-296

6 Senf P, Schmitz B, Holtkamp M, Janz D. Prognosis of juvenile myoclonic epilepsy 45 years after onset: seizure outcome and predictors. Neurology 2013;81(24):2128-2133

7 Holtkamp M, Senf P, Kirschbaum A, Janz D. Psychosocial long-term outcome in juvenile myoclonic epilepsy. Epilepsia 2014;55(11):1732-1738

8 Hernández-Vanegas LE, Jara-Prado A, Ochoa A, et al. Highdose versus low-dose valproate for the treatment of juvenile myoclonic epilepsy: going from low to high. Epilepsy Behav 2016;61:34-40

9 Calleja S, Salas-Puig J, Ribacoba R, Lahoz CH. Evolution of juvenile myoclonic epilepsy treated from the outset with sodium valproate. Seizure 2001;10(6):424-427

10 DiLiberti JH, Farndon PA, Dennis NR, Curry CJR. The fetal valproate syndrome. Am J Med Genet 1984;19(3):473-481

11 Tomson T, Battino D, Bonizzoni E, et al. EURAP Study Group. Dose-dependent teratogenicity of valproate in mono- and polytherapy: an observational study. Neurology 2015;85(10): 866-872

12 Viswanathan LG, Satishchandra P, Bhimani BC, et al. Polycystic ovary syndrome in patients on antiepileptic drugs. Ann Indian Acad Neurol 2016;19(3):339-343

13 Serafini A, Gerard E, Genton P, Crespel A, Gelisse P. Treatment of juvenile myoclonic epilepsy in patients of child-bearing potential. CNS Drugs 2019;33(3):195-208

14 Holtkamp M, Kowski AB, Merkle H, Janz D. Long-term outcome in epilepsy with grand mal on awakening: forty years of follow-up. Ann Neurol 2014;75(2):298-302

15 Geithner J, Schneider F, Wang Z, et al. Predictors for long-term seizure outcome in juvenile myoclonic epilepsy: 25-63 years of follow-up. Epilepsia 2012;53(8):1379-1386

16 Höfler J, Unterberger I, Dobesberger J, Kuchukhidze G, Walser G, Trinka E. Seizure outcome in 175 patients with juvenile myoclonic epilepsy-a long-term observational study. Epilepsy Res 2014;108(10):1817-1824

17 Harden C. Juvenile myoclonic epilepsy-what does the future look like? Epilepsy Curr 2014;14(3):150-151

18 Jain S, Padma MV, Maheshwari MC. Occurrence of only myoclonic jerks in juvenile myoclonic epilepsy. Acta Neurol Scand 1997;95(5):263-267

19 Stevelink R, Koeleman BPC, Sander JW, Jansen FE, Braun KPJ. Refractory juvenile myoclonic epilepsy: a meta-analysis of prevalence and risk factors. Eur J Neurol 2019;26(6):856-864

20 Guaranha MSB, Filho GM de A, Lin K, Guilhoto LMFF, Caboclo LOSF, Yacubian EMT. Prognosis of juvenile myoclonic epilepsy is related to endophenotypes. Seizure 2011;20(1):42-48

21 Canevini MP, Mai R, Di Marco C, et al. Juvenile myoclonic epilepsy of Janz: clinical observations in 60 patients. Seizure 1992;1(4):291-298

22 Seneviratne U, Cook M, D'Souza W. The prognosis of idiopathic generalized epilepsy. Epilepsia 2012;53(12):2079-2090

23 Raju PK, Satishchandra P, Nayak S, Iyer V, Sinha S, Anand A. Microtubule-associated defects caused by EFHC1 mutations in juvenile myoclonic epilepsy. Hum Mutat 2017;38(7):816-826 
24 Cavalleri GL, Walley NM, Soranzo N, et al. A multicenter study of BRD2 as a risk factor for juvenile myoclonic epilepsy. Epilepsia 2007;48(4):706-712

25 Vijai J, Kapoor A, Ravishankar HM, et al. Genetic association analysis of KCNQ3 and juvenile myoclonic epilepsy in a South Indian population. Hum Genet 2003;113(5):461-463
26 Kapoor A, Vijai J, Ravishankar HM, Satishchandra P, Radhakrishnan K, Anand A. Absence of GABRA1 Ala322Asp mutation in juvenile myoclonic epilepsy families from India. J Genet 2003;82(1-2):17-21

27 von Podewils F, Kowoll V, Schroeder W, et al. Predictive value of EFHC1 variants for the long-term seizure outcome in juvenile myoclonic epilepsy. Epilepsy Behav 2015;44:61-66 